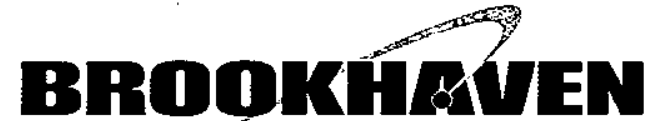 \\ NATIONÁL LABORATORY
}

BNL-79922-2008-CP

\section{RHIC polarized proton performance in Run-8}

C. Montag, N.P. Abreu, L. Ahrens, M. Bai, D. Barton,

A. Bazilevsky, J. Beebe-Wang, M. Blaskiewicz,

J.M. Brennan, K.A. Brown, D. Bruno, G. Bunce, R. Calaga, P. Cameron, R. Connolly, T. D'Ottavio, A. Drees, A.V. Fedotov, W. Fischer, G. Ganetis, C.J. Gardner, J.W. Glenn, T. Hayes, H. Huang, P. Ingrassia, D. Kayran, J. Kewisch, R.C. Lee, V. Litvinenko, A.U. Luccio, Y. Luo, W.W. MacKay, Y. Makdisi, N. Malitsky, G. Marr, A. Marusic, R. Michnoff, J. Morris, B. Oerter, H. Okada, F. Pilat, P. Pile, G. Robert-Demolaize, T. Roser, T. Russo, T. Satogata, C. Schultheiss, M. Sivertz, K. Smith, S. Tepikian, D. Trbojevic, N. Tsoupas, J. Tuozzolo, A. Zaltsman, A. Zelenski, K. Zeno, S.Y. Zhang

Presented at the $11^{\text {th }}$ Biennial European Particle Accelerator Conference (EPAC 2008) Genoa, Italy June 23-27, 2008

\author{
Collider-Accelerator Department \\ Brookhaven National Laboratory \\ P.O. Box 5000 \\ Upton, NY 11973-5000 \\ unw.bnl.gov
}

\begin{abstract}
Notice: This manuscript has been authored by employees of Brookhaven Science Associates, LLC under Contract No. DE-AC02-98CH10886 with the U.S. Department of Energy. The publisher by accepting the manuscript for publication acknowledges that the United States Government retains a non-exclusive, paid-up, irrevocable, world-wide license to publish or reproduce the published form of this manuscript, or allow others to do so, for United States Government purposes.
\end{abstract}

This preprint is intended for publication in a journal or proceedings. Since changes may be made before publication, it may not be cited or reproduced without the author's permission. 


\section{DISCLAIMER}

This report was prepared as an account of work sponsored by an agency of the United States Government. Neither the United States Government nor any agency thereof, nor any of their employees, nor any of their contractors, subcontractors, or their employees, makes any warranty, express or implied, or assumes any legal liability or responsibility for the accuracy, completeness, or any third party's use or the results of such use of any information, apparatus, product, or process disclosed, or represents that its use would not infringe privately owned rights. Reference herein to any specific commercial product, process, or service by trade name, trademark, manufacturer, or otherwise, does not necessarily constitute or imply its endorsement, recommendation, or favoring by the United States Government or any agency thereof or its contractors or subcontractors. The views and opinions of authors expressed herein do not necessarily state or reflect those of the United States Government or any agency thereof. 


\section{RHIC Polarized Proton Performance in Run-8 *}

C. Montag, N. Abreu, L. Ahrens, M. Bai, D. Barton, A. Bazilevsky, J. Beebe-Wang, M. Blaskiewicz, J.M. Brennan, K.A. Brown, D. Bruno, G. Bunce, R. Calaga, P. Cameron, R. Connolly, T. D' Ottavio,

A. Drees, A.V. Fedotov, W. Fischer, G. Ganetis, C. J. Gardner, J. W. Glenn, T. Hayes, H. Huang, P. Ingrassia, D.A. Kayran, J. Kewisch, R.C. Lee, V.N. Litvinenko, A.U. Luccio, Y. Luo,

W.W. MacKay, Y. Makdisi, N. Malitsky, G. Marr, A. Marusic, R. Michnoff, J. Morris, B. Oerter, H. Okada, F. Pilat, P. Pile, G. Robert-Demolaize, T. Roser, T. Russo, T. Satogata, C. Schultheiss, M. Sivertz, K. Smith, S. Tepikian, D. Trbojevic, N. Tsoupas, J. Tuozzolo, A. Zaltsman,

A. Zelenski, K. Zeno, S.Y. Zhang, Brookhaven National Laboratory, Upton, NY 11973, USA

\begin{abstract}
During Run-8, the Relativistic Heavy Ion Collider (RHIC) provided collisions of spin-polarized proton beams at two interaction regions. Helical spin rotators at these two interaction regions were used to control the spin orientation of both beams at the collision points. Physics data were taken with different orientations of the beam polarization. We present recent developments and improvements as well as the luminosity and polarization performance achieved during Run-8.
\end{abstract}

\section{INTRODUCTION}

The RHIC polarized proton run in fiscal year 2008 (Run8) lasted for six weeks, from January 28 to March 10 . Included in this time are the necessary start-up of the machine, and the actual physics run. The main objective of this run was to provide proton-proton collisions for comparison purposes with the preceding deuteron-gold run [1] for the STAR detector, and to develop the machine towards higher luminosity in future runs.

\section{MACHINE CONFIGURATION AND SET-UP}

Since luminosity performance in Run-6 had been limited by beam-beam effects [2], a new near-integer working point had been proposed and extensively studied in both simulations and experiments [3]; however, the latter had been limited to studies at injection energy. The dynamic aperture was found to be significantly larger at the near-integer working point than at the Run- 6 tunes of (.685/.695). Therefore, the initial set-up was performed with the "Blue" ring at store tunes of $(.96 / .95)$, while the "Yellow" working point remained unchanged from Run-6, at $(.695 / .685)$ [4].

When first collisions were provided to the experiments after one week of machine set-up, detector backgrounds from the "Blue" beam were found to be unacceptably high. These backgrounds could be traced back to the enhanced

\footnotetext{
* Work performed under US DOE contract DE-AC02-98CH1-886
}

\begin{tabular}{lr}
\hline Beam energy [GeV] & 100 \\
No. of bunches/beam & 109 \\
No. of protons/bunch $\left[10^{11}\right]$ & 1.5 \\
emittance $[\mu \mathrm{m}]$ & $20-25$ \\
$L_{\text {peak }}\left[10^{30} \mathrm{~cm}^{-2} \mathrm{sec}^{-1}\right]$ & 35 \\
$L_{\text {store avg. }\left[10^{30} \mathrm{~cm}^{-2} \mathrm{sec}^{-1}\right]}$ & 23 \\
$\beta^{*}[\mathrm{~m}]$ & 1.0 \\
No. of collision points & 2 \\
Spin orientation at PHENIX & vertical \\
Spin orientation at STAR & vertical \\
\hline
\end{tabular}

Table 1: RHIC parameters during the polarized protons physics run.

$10 \mathrm{~Hz}$ orbit oscillation amplitude at near-integer tunes [4]. The new working point therefore had to be abandoned, and the set-up from Run- 6 was reloaded.

Since RF and instrumentation timing set-up had already been done with the near-integer working point configuration, it took less than 24 hours to provide colliding beams. After some more tuning the ramp reached sufficient transmission efficiency to allow for acceleration of 109 bunches per ring, and development of the rotator ramp to provide radial spin orientation at PHENIX began.

During the rotator ramp development emittances at store were found to be significantly larger than at injection. The rotator ramp, which takes about 30 minutes for a full cycle, was therefore abandoned to speed-up investigations of the emittance blow-up problem. Table 1 lists the machine configuration and parameters used during the physics run.

\section{PERFORMANCE}

\section{Luminosity}

Working points of the two rings were both placed below the diagonal; the necessary tune separation to avoid coherent beam-beam effects was achieved by separating the two working points along the $Q_{x}=Q_{y}$ diagonal, rather than by mirroring them across the diagonal. In contrast to the Run- 6 experience, no obvious beam-beam limit was ob- 
served in this configuration. Bunch intensities of $1.6 \cdot 10^{11}$ protons/bunch were routinely injected and accelerated; the maximum achieved bunch intensity reached $1.8 \cdot 10^{11}$ protons/bunch. This resulted in typical peak luminosities of $30 \cdot 10^{30} \mathrm{~cm}^{-2} \mathrm{sec}^{-1}$ at the beginning of physics stores, and average store luminosities around $23 \cdot 10^{30} \mathrm{~cm}^{-2} \mathrm{sec}^{-1}$, as shown in Figure 1. The delivered integrated luminosity

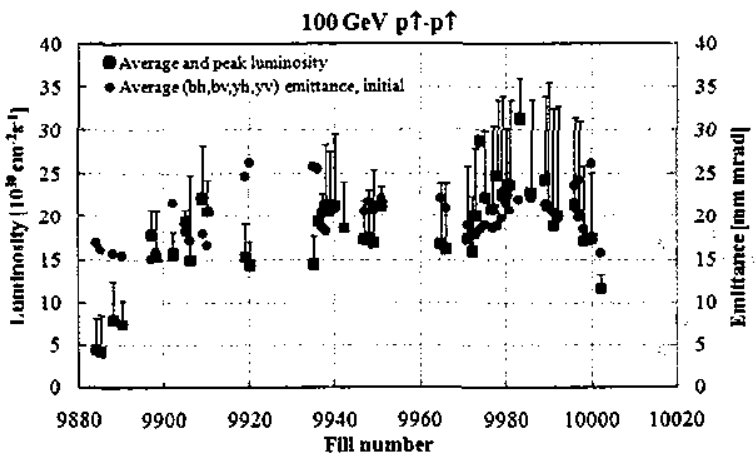

Figure 1: Peak (vertical bars) and average (red squares) luminosity vs. store number during Run- 8 polarized protons operations. The blue dots indicate the average beam emittance as calculated from measured luminosity and beam intensities, assuming round beams of equal emittance.

reached about $18 \mathrm{pb}^{-1}$, close to the maximum projection. As Figure 2 shows, this is more than twice the integrated luminosity delivered during the same initial period of the Run- 6 polarized protons run. This faster build-up of inte-

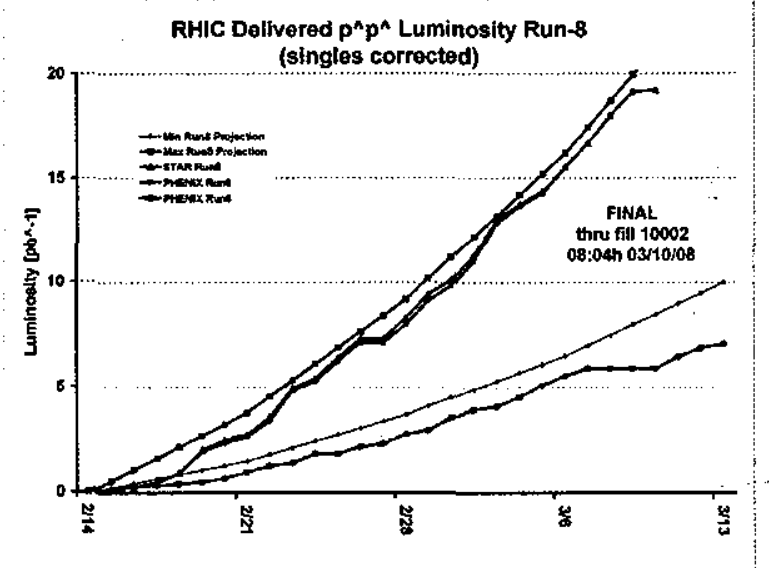

Figure 2: Integrated delivered luminosity for the two experiments PHENIX (blue) and STAR (red) during the course of the run. For comparison, the integrated delivered luminosity during the same period in Run-6 is included (green line). The minimum and maximum projections for Run- 8 are indicated by the two smooth lines.

grated luminosity was due to reloading a high-performing machine configuration from the end of the Run- 6 polarized protons operations period, as well as due to a higher av- erage time in store, which reached 59.52 percent of total calendar time. As Figure 3 illustrates, the latter constitutes a new record in RHIC operations.

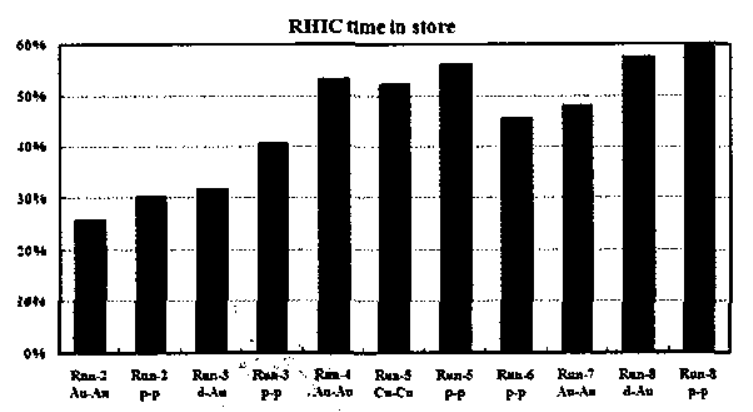

Figure 3: Average time in store for all runs since 2001, as fraction of the total calendar time.

\section{Polarization}

The relevant figure-of-merit for collisions of transversely polarized protons is $L \cdot P_{\text {Bluc }} \cdot P_{\text {Yellow }}$, where $L$ is the luminosity, and $P_{\mathrm{Bluc}}$ and $P_{\text {Yellow }}$ denote the polarization of the "Blue" and "Yellow" beam, respectively. In Run-8 the integrated figure-of-merit reached $3.9 \mathrm{pb}^{-1}$, which is well above the projected minimum of $2.5 \mathrm{pb}^{-1}$, as shown in Figure 4. On the other hand, the achieved integrated figureof-merit falls short of the projected maximum of $7.7 \mathrm{pb}^{-1}$ by a factor of two, in spite of the integrated luminosity being close to the projected maximum. This is due to the rather low polarization of typically 50 percent in the "Blue" and 40 percent in the "Yellow" ring (Figure 5), compared to 60 percent in Run- 6 .

There are multiple reasons for the low polarization. First

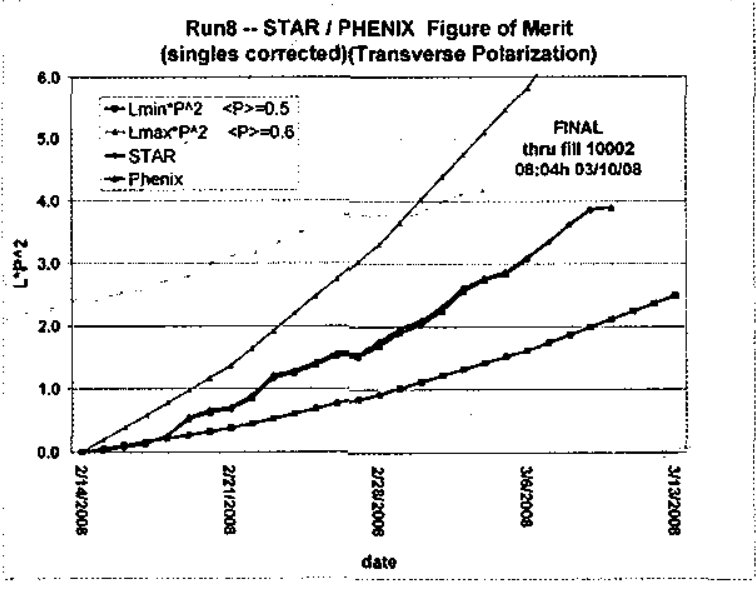

Figure 4: Integrated delivered figure-of-merit $L \cdot P_{\mathrm{Blue}}$. $P_{\text {Yellow }}$ for the two experiments PHENIX (blue) and STAR (red) during the course of the run, together with the minimum and maximum projections (smooth lines).

of all, the beam polarization at the source reached only 


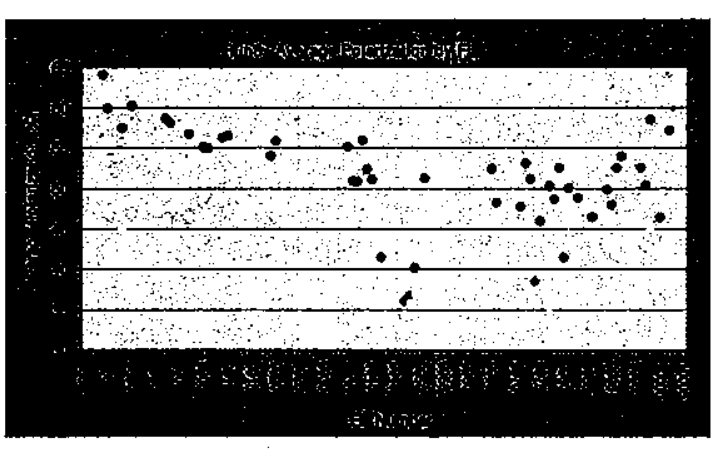

Figure 5: Average polarization vs. fill number in the two RHIC rings, "Blue" and "Yellow".

about 80 percent, vs. 85 percent in Run-6. Furthermore, the AGS was set up in a new "injection-on-the-fly" mode, aiming at increasing the polarization beyond the previously achieved level of 65 percent due to a faster ramp rate across the lowest-energy depolarizing resonance [5]. However, the polarization at AGS extraction turned out to be lower than in Run-6. Additionally, a strong intensity dependence of the extraction polarization was observed. Therefore, the Run-6 set-up of the AGS was reloaded for the final week of the physics run.

In addition, the polarization transmission in the "Yellow" RHIC ring was significantly lower than in the "Blue" ring, at times only around 75 percent. The most likely cause for this loss of polarization on the ramp in the "Yellow" ring is a horizontal orbit angle through the two Siberian snakes, which are located at two positions across the diameter of the ring. If the orbits through these two devices are not parallel, the resulting spin tune significantly deviates from the ideal value of $\nu_{\text {spin }}=1 / 2$. This in turn leads to depolarizing resonances each splitting into pairs, thus effectively reducing the available resonance-free tune space between resonances. Unfortunately, beam position monitors in the vicinity of one of the snakes were unavailable, so the actual orbit through this particular snake is unknown. Furthermore, the potential problem of non-parallel orbits through the snakes was not realized until two days before the end of the run, which did not leave sufficient time to perform an orbit angle scan.

\section{MACHINE DEVELOPMENT}

As a path to increased luminosity in future runs, the $\beta$ function at the two IPs was reduced from the operational value of $\beta^{*}=1.0 \mathrm{~m}$ to $0.68 \mathrm{~m}$ during several dedicated development periods [6]. Up to 56 bunches in both rings were accelerated and brought into collision. The luminosity scaled well with the reduced $\beta^{*}$, and detector background rates were at similar levels as with the regular ramp. After correcting the nonlinear chromaticity at store energy, lifetimes were acceptable.

\section{SUMMARY}

The polarized proton operations during Run- 8 was successful, despite the short duration of only six weeks. Weekly integrated luminosities reached levels similar to those in Run-6, the latest polarized protons run. However, polarization levels in both rings were significantly lower than in Run-6. During a long run, there would have been sufficient time to improve beam polarizations by systematically scanning various parameters in both the AGS and RHIC.

The reduced $\beta^{*}$ is expected to significantly increase the luminosity in Run- 9 and beyond. Installation of a new $9 \mathrm{MHz}$ cavity should reduce the longitudinal emittance by a factor two, thus overcoming the associated increased hourglass effect. Additionally, this cavity will also likely reduce the incoherent emittance growth at injection [7].

\section{REFERENCES}

[1] C. J. Gardner et al., "Setup and Performance of RHIC for the 2008 Run with Deuteron and Gold Collisions", these proceedings

[2] V. Ptitsyn et al., "RHIC performance as polarized protons collider in Run-6", Proc. EPAC 2006

[3] C. Montag et al., "A Near-Integer Working Point for Polarized Protons in the Relativistic Heavy Ion Collider", Proc. PAC 2007

[4] C. Montag et al., "Operational Experience with a Nearinteger Working Point at RHIC", these proceedings

[5] H. Huang et al., "AGS Polarized Proton Operation in Run 8", these proceedings.

[6] F. Pilat et al., "Reduction of Beta* and Increase of Luminosity at RHIC", these proceedings

[7] S. Y. Zhang and V. Ptitsyn, "Proton beam emittance growth in the Relativistic Heavy Ion Collider", Phys. Rev. ST Accel. Beams 11, 051001 (2008) 